\title{
Some Distinct Types of Distribution of Cytoplasmic Ribonucleic Acid with Related Changes of Cytochondria in Liver Cells under Normal and Pathological Conditions

\author{
By
}

\author{
Atuhiro Sibatani
}

(With 11 Text-Figures)

Received November 5, $194 \%$.

I (Sibatani, 1948a) have recently reported that the pyroninophilic substance in the cytoplasm of vertebrate liver cells, which was described and identified with stored protein by BERG (1912, 1920,1922, 1928) and ClARA (1934), may rather be regarded as consisting of ribonucleic acid and therefore be ranged into the ergastoplasm. It has also been proved by DAVIDSON and WAYMOUTH (1943-44) or OPIE and LAVIN (1946) that basophilic substance in the hepatic cytoplasm absorbs ultraviolet radiation of wave length $2527 \mathrm{~A}$ and can be removed by ribonuclease; this indicates the ribonucleic acid nature of the substrate. According to BERG, the "pyroninophilic substance" is found in the cytoplasm in the form of homogeneous droplets of varying size and shape, but this interpretation seems to be incorrect. Ribonucleic acid may rather be interpreted to exist in the interspace between or on the surface of the granular bodies in the cytoplasm (SIBATANI, 1948a). A similar statement has already been published by OPIE $(1947 \mathrm{a}, \mathrm{b})$, who has designated the granular bodies with definable rim and clear central space, inclusive of mitochondria, for convenience, cytochondria, in or upon which surface ribonucleic acid is present. Although it is necessary to analyse the relation between cytochondria, secretion granules and also lipochondria, OPIE's terminology may be adopted for the moment. Mitochondria have, as discussed later, to be distinguished from the granules with definable and frequently basophilic rim and clear central space, and so I exclude here mitochondria from the conception of the cytochondria.

The gradual disappearance of the "pyroninophilic substance" during starvation or in case of adrenalin poisoning has been repeatedly observed by BeRG (1912, 1920), STÜBEL (1920) and others. Also OPIE (1946) has recently reported the mobilization of ribonucleic acid in the liver cytoplasm with the production of tumors. As for the cytochondria, OPIE (1947a, b) has mentioned that pathological changes bring about such an enlargement of them that the entire cytoplasm assumes a foam-like appearance. The purpose of this paper is, on the same line of investigations, to establish 
some distinct types of distribution of cytoplasmic ribonucleic acid with related changes of cytochondria under normal and pathological conditions.

The essential of staining mechanism of nucleic acids with basic dyes may be believed to consist in the salt-formation between these substances. As I have shown elsewhere (SIBATANI, 1948a, b), at least two sorts of nucleates of a single basic stain differing in chemical and physical properties from each other, can be formed in the test-tube reaction: the one, soluble in water, is produced with the excess of nucleic acid, and is expected as a primary acidic salt; and the other, probably a secondary salt, is usually insoluble in water and readily precipitated on mixing the aqueous solution of a nucleic acid with the excess of the solution of a basic stain. In cases where thionine or other allied stains are used as a basic dye, it has been found that these two dye nucleates are distinguished from each other by their different colors. For example, the color of the watersoluble thionine ribonucleate is blue, while that of the precipitate is reddish purple. Now, these colors of two thionine ribonucleates are in good accordance with metachromasia of nucleic acids in liver cells stained with thionine: the chromatin containing desoxyribonucleic acid stains in blue while ergastoplasm and nucleoli which consists of ribonucleoproteins stain in reddish purple or violet.

The formation of these two different-colored substances in a single cell indicates not necessarily the presence of chemically different nucleic acids, because a unique yeast ribonucleic acid has been found to form two different salts showing typical color difference with thionine, but siggests that the characters of the chemical union of nucleic acids with basic proteins differ from each other in chromatin and in ergastoplasm or nucleoli. It could not, however, be decided up to the present whether this difference of the staining properties of nucleoproteins is conditioned by the difference of their nucleic acids. So we can not yet go very far in establishing directly that desoxyribo- and ribonucleoproteins stain with thionine in blue and reddish purple, respectively.

The staining mechanism with pyronine-methyl green is in essential the same as with thionine (Sibatani, 1948c). Methyl green forms together with iodine green a remarkable exception among the basic dyes because they produce no precipitation with nucleic acids. Thus the ribonucleic acids in ergastoplasm or nucleoli react only with pyronine and hence stain in red, because these form water-insoluble secondary salts with usual basic dyes, and the staining effect or the formation of water-soluble secondary salt of methyl green is brocked completely by the presence of pyronine. The chromatin staining in light blue may be considered to suggest the formation of a mixture of primary pyronine and methyl green desoxyribonucleates. 
Since it has not yet been decidedly proved, whether the heterogeneity of the basophilic nature of nucleic acids in a cell, which manifests promptly when stained with thionine or pyronine-methyl green, depends upon the presence of different kinds of nucleic acids, it would be desirable to distinguish terminologically the different characters of basophilia caused by the reaction of nucleic acids in fixed tissues with basic stains. So I distinguish here the eubasophilia of chromatin and nuclear membrane from the heterobasophilia of ergastoplasm and nucleoli. The eubasophile nucleic acid in cells from water-soluble, probably acidic, primary salt when stained with basic dyes, thus stains in blue with thionine and in light blue or occasionally bluish green with pyronine-methyl green, and so on, and is represented presumably by desoxyribonucleic acid. On the contrary, the heterobasophile nucleic acid stains with basic dyes under formation of a precipitate of dye nucleate or a secondary salt, and therefore in reddish purple or violet with thionine and in red with pyronine-methyl green, and corresponds presumably to ribonucleic acid.

\section{Material and Methods}

The present study was made mainly with livers of white rats. Livers of other experimental animals were, if necessary, used for comparison. 'To fix the cytoplasmic ribonucleic acids 10 per cent formalin was as usefuI as alcohol-formalin or fluids of BoUIN, CARNOY and HELLY. Unless it deals with exact quantitative determination, the formalin fixation was found to exert no unfavorable consequence upon preserving and detecting the ribonucleic acid in the cytoplasm. Indeed, it is of great covenience in the morphological study to be able to be able to use formalin as a fixative, because this is employed most frequently in pathological investigations, towards which cytological foundation the present work intends to contribute. The paraffin sections were stained usually with 0.5 per cent aqueous solution of thionine.

In the studies of cytoplasmic ribonuceic acid of liver scells pyroninemethyl green of UNNA-PAPPENHEIM was used almost exclusively since BERG's (1912) original description. To differentiate heterobasophile ergastoplasm and nucleoli from eubasophile chromatin in colors by staining technique, it would be desirable to employ pyronine-methyl green rather than thionine, since with the former hereto- and eubasophile nucleoproteins stain in red and light blue, respectively, while with the latter the corresponding color difference is not so remarkable as the former: reddish purple and blue. The relation between ribonucleic acid and cytochondria is, however, demonstrated more clearly with thionine. Studying especially the cytochondria, OPIE (1947b) has employed Giemsa stain and its modification to distinguish the cytochondria with basophilic rim from those 
without it. A similar effect can be attained with toluidine blue-eosin or allied stains. But the introduction of an acidic dye as a counterstain makes it difficult, to elucidate delicate structures containing ribonucleic acids of the cytoplasm.

\section{Observations}

The morphological changes of cytoplasmic ribonucleic acid and cytochondria in liver cells may be classified into the following four types. The first that appears in livers of animals fed with abundant proteins is considered as the normal or principal type. Livers of dying or dead animals in consequence of various infections, chemical poisonings, burns, or starvation show a sharp contrast with the normal type, representing a type of "catastrophe." The remaining two are regarded as forming intermediate types on two different lines between these extremities; the one is often observed when animals are slightly injured by various factors, suggesting a state of active metabolism; the other seems to appear almost constantly in recovering from injuries. These two types may, however, be observed not rarely among animals under usual breeding conditions, but more frequently in cases with relatively insufficient nutrition, especially of protein nature, and also probably in connexion with daily or working rhythms of hepatic cells. It is also possible that complex or intermediary cases appear with partial characteristics of several types. In the following these types will be described in detail. On the morphology of the nucleus will not be mentioned on purpose, because I am not sure whether it always goes parallelly with changes of the cytoplasm. It will be described when different factors affecting liver cells are dealt with separately in papers prepared to be published successively.

Type I. Normal or principal type appearing with administration of sufficient nutrition of protein nature (Figs. 1-4).

Characteristics: Heterogeneous distribution of ergastoplasm occurring in abundance; minute cytochondria; relatively small quantitity of vacuoles (aqueous inclusions).

This type has been described repeatedly by BERG $(1912,1920,1928)$, STÜBEL (1920), ClARA (1934) and others in liver cells of different mammals and especially of salamanders which had received sufficient quantity of proteins or their cleavage products. The heterobasophile ergastoplasm has been interpreted by these authors to form several droplets of very viscous fluid, varying in size and shape. Although in this type the ergastoplasm or ribonucleic acid is condensed into several compact masses, it is localized rather in the interspace between or on the surface of certain groups of the cytochondria than within the formed granules themselves, 
thus resembling droplets scattered in the cytoplasm. For example, in Fig. 1 the ergastoplasm assumes an appearance of such discrete bodies of condensed masses that we are readily inclined to consider that they would exist in the cytoplasm independently of other structural elements, possessing their own forms and surfaces. But a comparison of Fig. 1 with Figs. 2-4 reveals that the real and parmanent structural elements are rather minute granular bodies or cytochondria which are originally not basophile, and of which surface the ribonucleic acid covers as the heterobasophile rim, and that this may accumulate so densely that it is almost impossible to distinguish the cytochondria through the thick envelopes of ribonucleic acid which condenses into some distinct masses in cytoplasm. This relation may also be understood without difficulties from the original figure of BERG (1920, pl. 32 fig. 1) showing a liver cell of salamander. BERG has considered the cytochondria with basophile rim of ribonucleic acid
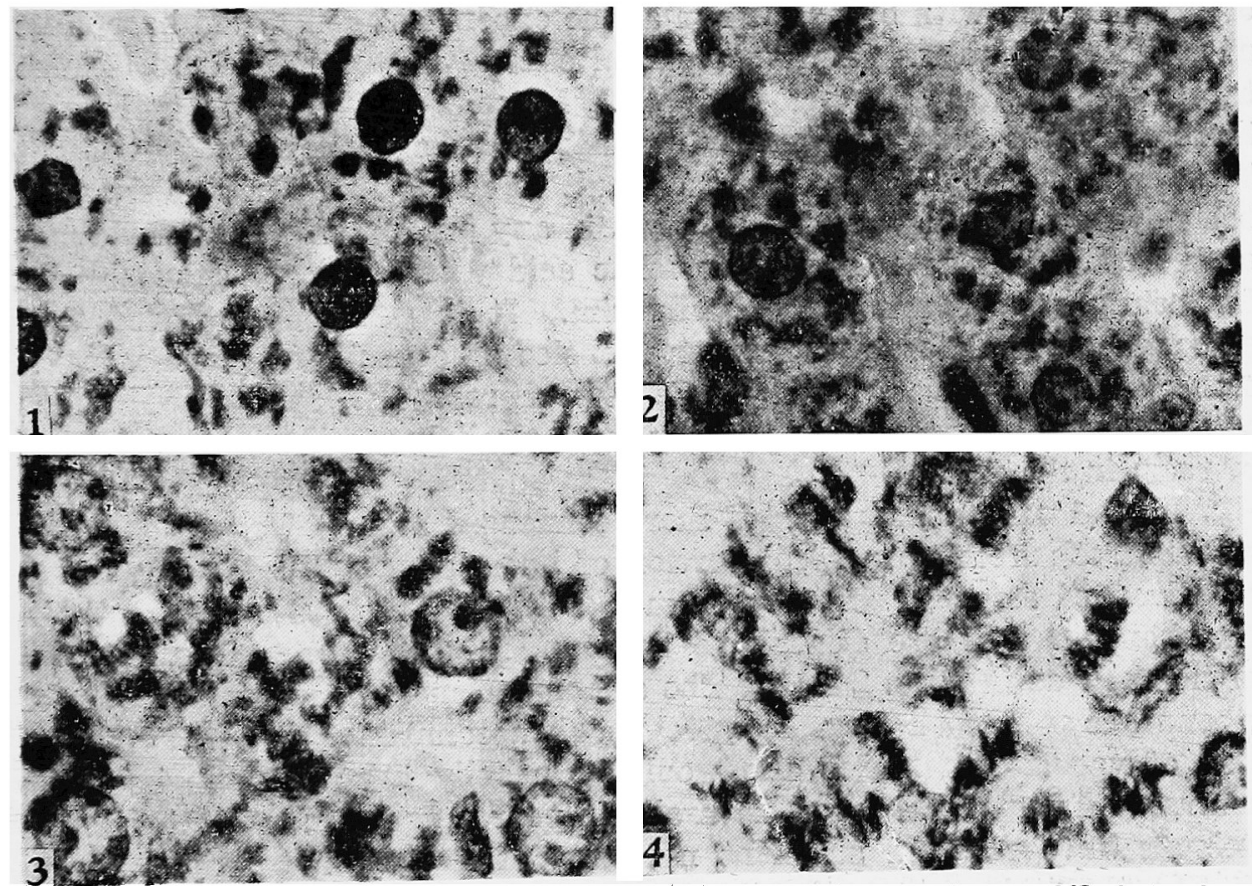

Figs. 1-4. Liver cells of rats; type I or normal type of the cytoplasm. All photomicrographs in the present paper were made with preparations fixed in 10 per cent formalin graphs in the present paper wer: K 8 and objective: HI 90 (Zeiss); $\times 1500$. Fig. 1. To and stained with thionine: ocular: $K 8$ and in cells about a central vein at an advanced show condensed masses of ribonucleic acid in cells about a central vein at an advanced stage of recovery from starvation. The rat was killed after 2 days from the beginn ng of readministration of foods after starvation during 3 days. $\%$. To show a relatively condensed state of abundant ergastoplasm in cells about a central vein of liver after administration state of abundant ergastoplasm in show a moderately accumulated state of ergastoplasm of protein during 2 weeks. in cells about a central vebule of the same liver as of Fig. 3. 
as a vacuolated state of the original condensed "droplets." This interpretation could hardly be maintained if it is noticed that the outline of the condensed masses of ribonucleic acid is, if observed precisely, always very irregular, and that as the condensed masses of nucleic acid tend to spread over the cytoplasm, the "vacuolated droplets" increase in number and often fill up the whole cytoplasm (Fig. 5), in whose interspace the remaining masses of ribonucleic acid can easily be observed.

Figs. 3 and 4 show the cells with moderately accumulated ribonucleic acio about a central vein and at the periphery of a lobule of the same liver, resp. The condensation of a larger amount of heterobasophile ribonucleic acid is always observed in the portion around central veins. The peripheral cells contain usually more vacuoles or aqueolis inclusions, and the ergastoplasm of these cells is less abundant and less condensed. But sometimes a reticular appearance is assumed with the meshes of clear central space of cytochondria with basophile rim at the expense of condensed basophilic masses and vacuoles. These peripheral cells are thus inclined to assume the characteristics of types II or IV. In cells about the central veins there are numerous acidophile cytochondria almost or completely without basophile rim, which are usually difficult to detect if stained sulely with basic dyes, unless they adsorb the stain in any grade, except the periphery of the condensed masses of ribonucleic acid where the cytochondria are frequently with definable basophile rim. It is generally believed that glycogen accumulates in the larger vacuoles as ergastic inclusions, but it seems to be somewhat doubtful that they represent always accumulations of ergastic substances soluble in water or alcohol, suggesting the amount of them in the cell.

Figs. 1 and 2 show cells of more condensed states of ergastoplasmic masses, both from the central portion of liver lobules. Fig. 1 represents an advanced stage of recovery from starvation, the cells do not contain cytochondria that are difficult to be seen in the photomicrograph so abundantly as in Figs. 2 or 3 . The accumulation of condensed masses of ribonucleic acid and acidophile cytochondria accompanied with the elimination of vacuoles of larger size would be usually introduced in both the central and peripheral areas, naturally in poorer grade in the latter, when animals have received sufficient nutrition of protein nature.

Lastly, it is noteworthy that in the cytoplasm there are some condensations of ribonucleic acid attaching here and there laterally to both sides of a row of several cytochondria that stand closely side by side, instead of forming a discrete rim around each of these cytochondria; they assume a form of two (or occasionally more) parallelly arranged short rods or filaments that resemble distinctly the "basal filaments" described by SOLGER (1896) in cells of salivary glands, which have been 
designated later by GARNIER (1899) "ergastoplasm"

This type has been ascertained by the author to occur not only in mammals such as rats, mice, or rabbits, but also among avian and amphibian livers.

Type II. Type of reacting state presumably with considerable metabolic activity by means of the consumption of cell proteins (Figs. 5 \& 6).

Characteritics: Homogeneous distribution of a relatively large amount of ergastoplasm; numerous minute cytochondria forming meshes together with the basophile rims of ribonucleic acid; vacuoles unprominent or entirely lacking.

This type appears readily with beginning of starvation and are retained until the following type takes place. STÜBEL (1920) has described this type in cases of starvation and of administration of adrenalin, and mentioned that the originally compact masses are replaced by fine rodshaped bodies staining with pyronine. BERG (1928) has interpreted that these bodies are no more than the mitochondria which are stainable occasionally with pyronine, and the true pyroninophilic substance (ergastoplasm) is urged to disappear in these cases. These inacurate observations and interpretations are almost inevitable if one stains the cells with
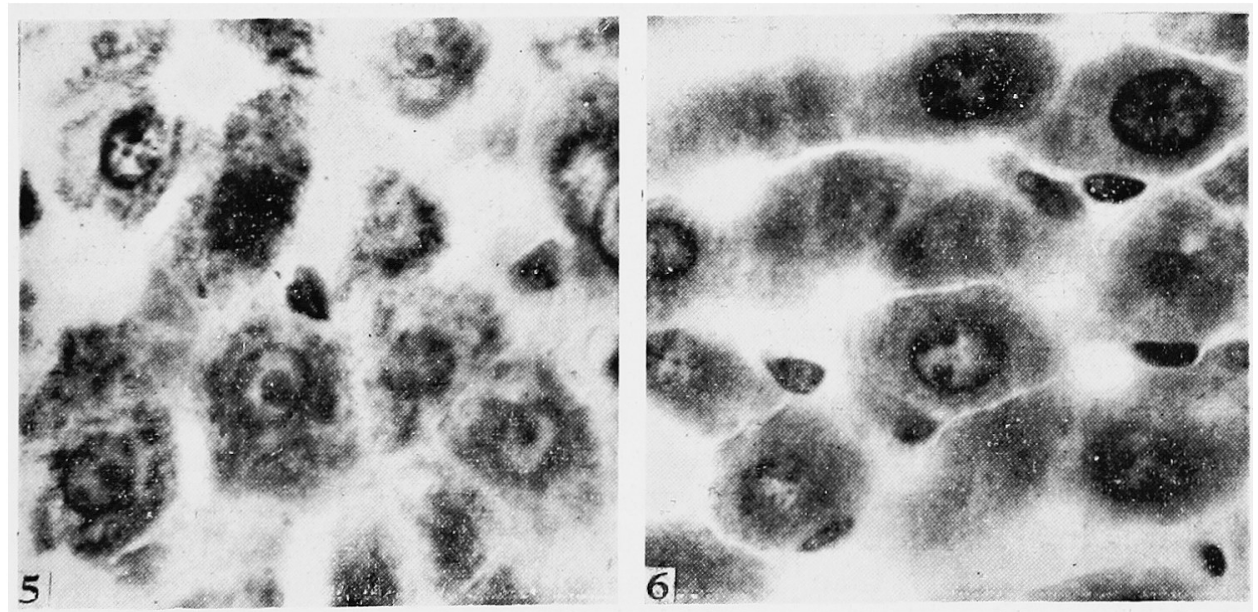

Figs. 5-6. Liver cells of rats: type II or reaction type of the cytoplasm. Cells about central veins. 5. To show the beginning state of the type II following starvation during 2 days. 6. To show a homogeneous distribution of abundant ergastoplasm in a typical state of the type II. The rat was injecte 1 subcutaneously with 1 per cent aq. soln. of ammonium lactate neutralized with $\mathrm{NH}_{4} \mathrm{OH}$ (daily ca. 0.5 cc. per $100 \mathrm{gr}$. of body weight) during 4 days and killed after 24 hours from the last injection. Because the rat has received relatively poor nutrition of protein nature, it is somewhat doubtful whether the ammonium lactate actually promoted the appearance of the type II. Malnutrition and starvation cause the appearance of such states much more constantly. 
pyronine-methyl green, because by this method cytochondria largely fail to prove their distinct individualities.

On staining with thionine it is revealed that the ergastoplasm never disiributed homogeneously over the whole cytoplasm which is packed of normal type disintegrate partially or entirely. The ergastoplasm is distributed homogenecusly over the whole cytoplasm which is packed densely with minute cytochondria, along whose interspace or surface the ribonucleic acid has been able to spread (Figs. 5 and 6 ). The cytochondria are thus all with basophile rim which assumes in several places the filamentous structure parallel to each other as a result of lateral attachment of neighboring cytochondria. The disintegration of the condensed masses of ribonucleic acid is either complete (Fig. 6) or incomplete (Fig. 5). In the latter case the remaining masses are visible among the reticular or finely foam-like structure of cytoplasm packed with cytochondria.

It is a remarkable fact that the typical cases of the homogeneous distribution of ribonucleic acid are acompanied almost without exception by the dissociation of cells.

The change into the type II from the normal type oecurs in the first place among the peripheral cells of a lobule and then tends to spread centripetally over the whole lobule. Cells of the central areas are the most resistant to this change. But in typical cases all parts of a lobule may show completely equal figures.

Type II has been observed by the author in livers of rats, mice, and guinea pigs.

Type III. Type of "catastrophe" appearing in livers of premortal, dying, and dead animals in consequence of various infections and other metabolic disturbances (Figs. 7-9).

Characteristics: A coarse, reticular or foam-like structure composed of enlarged cytochondria always with delicate rim of poor ergastoplasm; occasional round vacuoles of moderate size.

This type has been observed by STÜBEL (1920) in advanced stages of starvation and of adrenalin poisoning, the material being rats. He has described in accordance with BERG $(1912,1920)$ that "the clump of protein" (which are no more than the condensed masses of ribonucleic acid or ribonucleoprotein) disappear entirely in these cases. OPIE (1947a, b) has recently reported that cytochondria may become swollen in cases of hepatoma produced by butter yellow, by chloroform poisoning, and by immersion of tissues in hypotonic solutions. A foam-like appearance of the cytoplasm caused by the cytochondrial enlargement may also be observed in association with postmortal autolysis.

These observations seem to suggest that the enlargement of cyto- 
chondria indicates a metabolic catastrophe of animals subsequent to an enormous disintegration of body proteins.

Typical states of cytochondrial enlargement intra vitam are accompanied always by complete disintegration of the condensed masses of ergastoplasm, and hence usually follow the states of its homogeneous spreading all over the cytoplasm as described in type II. During the preceding period, represented by type II, the ribonucleic acid may be consumed to a large extent and becomes very poor or almost disappears in type III.

It is noteworthy that in this type the cell bodies show no considerable enlargement, and even an obvious contraction in cases of starvation, although the cytochondria contained in them are enlarged remarkably. Together with the tendency of basophilic rims of the cytochondria in types I and II described above to form some parallel filaments by the union of neighbornig basophilic rims consisting of ribonucleic acid, this fact may indicate that the enlargement of the cytochondria intra vitum takes place
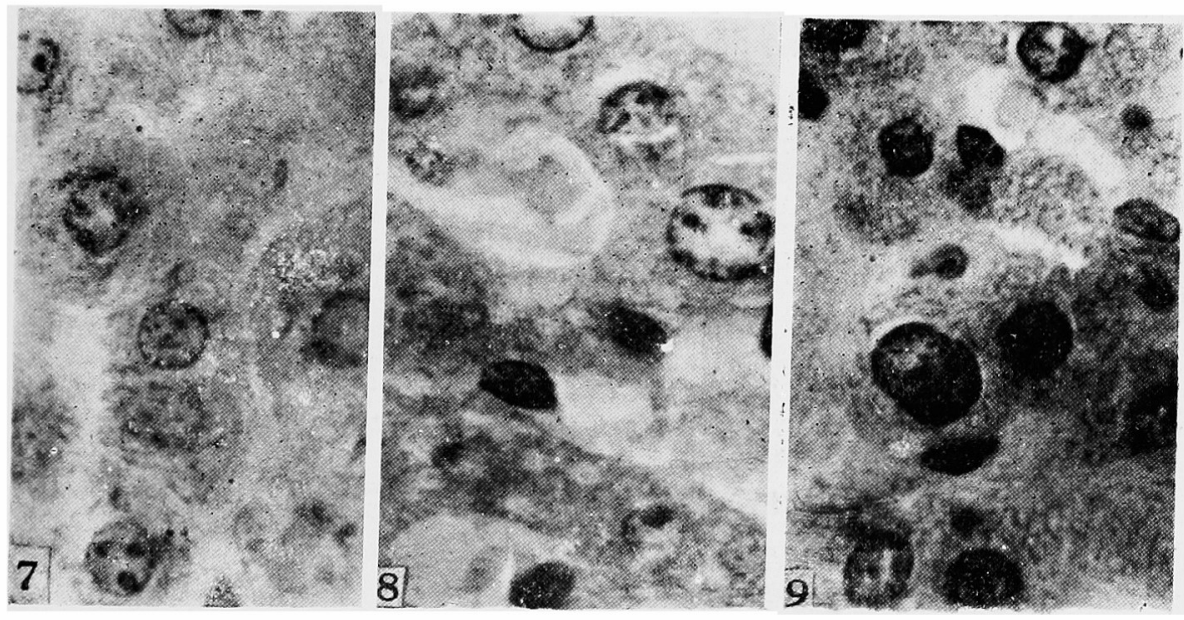

Figs. 7-9. Liver cells of rats ; type III or " catastrophe" of the cytoplasm. Cells about central veins. 7. An intermediary case of the types II and III, that has appeared after starvation during 5 days. 8 . To show the cells with enlarged cytochondria and round vacuoles. The animal died by an unidentified infection that attacked at the same time all the animals of one experiment (about 20 rats) with almost constant death. 9. To show cells with enlarged cytochondria and without any remarkable round vacuole, in a premortal state after starvation during 3 days.

rather by the mutual fushion of several cytochondria than their osmotic swelling as postulated by OPIE (1947b).

Such interpretation would be more reliable if it were considered that the filamentous structures of ergastoplasm have been found to occur abundantly in a intermediary case between the types II and III (fig. 7), 
in connexion with figures of lateral fusion of fairly enlarged cytochondria.

Round vacuoles of moderate size may be observed in many cases (Fig. $8)$, but their appearance is so irregular that their relation to a certain condition of disturbance or diseases could not be established. These vacuoles may be immediately distinguished from the almost vacuolated cytochondria because they have no definable rims of their own but are bounded directly by the assembly of basophile rims of the surrounding cytochondria. In other cases these vacuoles may be entirely lacking (Fig. 9).

This type has been observed in rats, mice, guinea pigs, pigs, horses: and also in man.

Type IV. Type of recovering state from injuries (Figs. $10 \& 11$ ).

Characteristics: An extraordinary swelling of cell bodies with considerable amount of hydropic vacuoles. Poor ergastoplasm and cytochondria that are either as in type I, II, or III.

The homogeneous states of the structures consisting of ribonucleic acid and of cytochondria as described in the two preceding types may be

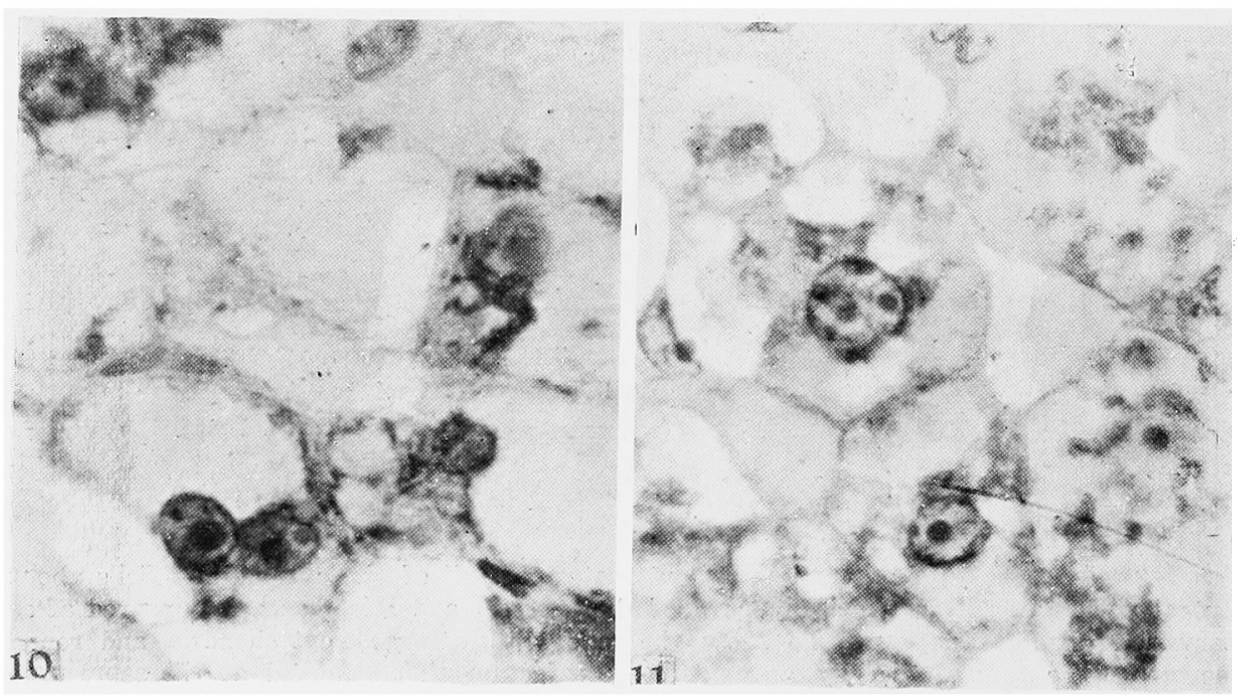

Figs. 10-11. Liver cells of rats; type IV or recovering type of the cytoplasm. Cells about central veins. 10. To show the beginning state of recovery from the type III. The animal has received foods for 2 days after starvation during 3 days. 11. To slow the state of recovery from an infect on that caused the death of the animal shown in Fig. 9. Killed after 5 days from the first appearance of symptoms of recovery.

found to be converted precipitately into their heterogeneous distribution with the entrance of animals into a restoration period. Some large hydropic vacuoles are seen to be occupying the larger part of the cyto- 
plasm, so that the nucleus is supported in the midst of the cell by means of some radial beams which consist of cytochondria, mitochondria, and ergastoplasm. Ergastoplasm may be either condensed into some compact masses that adhere very frequently to the cell-membrane and the nucleus; in this state a good number of minute cytochondria may be free from ergastoplasmic envelopes (Fig. 10); in other cases the ribonucleic acid may spread over all of the somewhat enlarged cytochondria as basophile rim maintaining the states of the types II or III (Fig. 11). The accumulation of the ergastoplasm and the elimination of the hydropic vacuoles may be restored more rapidly in cells about central veins than those of peripheral portions.

This type has been observed mainly in rats, but livers of guinea pigs may readily show this state of the cytoplasm under usual breeding conditions.

Intermediary forms of types II and IV may also be observed frequently: vacuoles are not so prominent and hence the cell bodies are not so swollen as in th ecases of type IV; minute cytochondria that are relatively abundant are all with delicate basophile rim, and except this there is no more ergastoplasm.

Relation of cytoplasmic ribonucleic acid to mitotic activity and to mitochondria. When liver cells are in mitosis no ergastoplasmic differentiation can usually be observed; this has been already found by ClARA (1934) in salamander. The disappearance of ergastoplasmic structures has also been reported by LoReti and PERRoncito (1938) in cells of parotids.

It is not uncommon that mitotic figures are seen in livers of white rats, in which the whole cytoplasm are composed almost uniformly of very minute cytochondrial granules and of faintly stained delicate network of very poor ribonucleic acid with occasional round vacuolar inclusions, although neighboring cells have abundant ergastoplasmic masses.

Similar observations have been made on several other tissues with heterobasophile cytoplasm. Thus the disappearance of ergastoplasm during mitosis seems to be a universal phenomenon. But in the intermediary cases of the types II and IV described above, it has been observed repeatedly that originally poor ergastoplasm scarecely changes its quantity in mitotic figures and the cytoplasmic reticular structures are not so homogeneous as in the usual cases of mitosis. It is, however, highly interesting and suggestive that a large amount of ribonucleic acid disappears usually from the cytoplasm to a remarkable dilution just at the same moment when desoxyribonucleic acid is accumulated in chromosomes by mitotic activity (CASPERSSON, 1941). 
It is desirable to make a brief reference on the spatial relation of mitochondria to cytochondria and ergastoplasm although I have not yet finished my investigations of this problem. Mitochondria seem, according to author's interpretation, to be localized in the interspace of the cytochondria, being attached upon the surface of them, thus overlapping with the ergastoplasm. This interpretation may be readily accepted when one refers to OPIE's photomicrographs (OPIE 1947b, Figs. $7 \& 8$ ) which show both the mitochondria and cytochondria. In these figures it may be observed without difficulty that the mitochondria are much smaller than the cytochondria, and are situated obviously in the interspace of the latter. Although it may be possible that mitochondria are enlarged in some cases to the dimension of cytochondria (cf. cells marked (A) of Fig. 8, OPIE, $1947 \mathrm{~b}$ ), it would not be appropriate to mix these two conceptions as proposed by OPIE (1947b).

\section{Discussion}

The statement that ergastoplasm contains ribonucleic acid in high concentration is not incompatible with the fact that the heretobasophile ergastroplasm of liver cells gives various reactions of proteins or their cleavage products. According to BERG (1912, 1922, 1928) and ClarA (1934) histochemical xanthoproteic, ninhydrin, Millon, and nitroprussid reactions have been found to be positive with this substrate. BERG has concluded especially on the basis of ninhydrin reaction the presence of lower molecules of protein nature in ergastoplasm. It must naturally be expected that ribonucleic acids are present, at least partially, as nucleoproteins in ergastoplasm. Furthermore, it is generally accepted that the presence of nucleic acids in cells indicates the center of active production of proteins, since CASPERSSON (1941) has proved that high concentrations of nucleotides in cells are always related with protein synthesis. Liver calls synthesize proteins continuously; this is naturally a prominent source of the blood proteins, which are again in dynamic equilibrium with the body proteins. The site of the synthesis of these proteins in liver cells is, then, without doubt, in the ergastoplasm. Therefore, the occurence of lower proteins in ergastoplasmic masses would not be contradictory with the argument postulating the nucleotide nature of them.

Although there is no discrepancy between the experimental facts indicating the presence of proteins and nucleic acids in the ergastoplasm, it is impossible to maintain BERG's $(1912,1920,1928)$ theory that the "pyroninophile droplets" represent a stored substance which must be distinguished from living protoplasm as a non-living matter. Recent advance of investigations with isotopes developed principally by SCHOEN- 
HEIMER and collaborators (cf. SCHOENHEIMER, 1942) has revealed the metabolic activities of organisms in their wonderful manifestation of the most dynamic state. The preserved materials can no longer be considered as non-living apart from the protoplasm in active metabolism, becaues they may also change their constituent molecules and radicals with certain inherent rhythms (SCHOENHEIMER and RITTENBERG, 1936).

The fact that the ergastoplasm in liver cells is accumulated by the administration of sufficient nutrition and disappears during starvation would seem to indicate that it would be preserved in cells. According to the modern conception of dynamic states of living protoplasm, which is in accordance with the consequence of theoretical considerations of the author (SIBATANI, 1947), proteins and nucleic acids must be synthesized and metabolized continuously in ergastoplasm. It has recently been proved by BARNES and SCHOENHEIMER (1943) that nucleic acids are synthesized from proteins and destroyed again rapidly in the organisms. According to the experiments of BRUES, TRACY and COHN (1944) ribonucleic acid turnover in the cytoplasm is considerably more active than that of desoxyribonucleic acid in the nucleus. Synthesis and decomposition of proteins and nucleic acids in cells must, therefore, be considered not separately but in the light of the conception of reciprocal causality as suggested by the author (SIBATANI, 1947).

It has been ascertained that ergastoplasm in livers and other tissues cannot be detected in fresh preparations (BERG, 1912; BABA and others, 1933; RIES, 1935, 1938; and LoReti e Perroncito, 1938) or when fixed with osmic acid (BERG, 1928). This fact indicates that ribonucleic acids are precipitated or coagulated by usual fixatives as chromatin and then attain their staining properties.

It has been discussed above that the ribonucleic acid is localized in the cytoplasm rather in the interspace or on the surface of the cytochondria, overlapping with mitochondria, than within the cytochondria themselves. The presence of ribonucleic acid in association with the formed elements of the cytoplasm has also been reported by many authors. Lipochondria of RIES (1935) are characterized by their ability to accumulate basic stains within them; this is caused appreciably by the presence of ribonucleic acid. With liver cells, MoRIBE (1933) has reported that basic stains are accumulated in the cytoplasmic granules by supravital staining. RIES' theory of lipochondria is related to Golgi bodies, which are held by WORLEY (1946) as temporary aggregation of ultramicroscopic colloidal particles containing phospholipids and ribonucleic acid. These findings must be considered in relation with microsomes which have been described by CLAUDE and FULLAM (1946) by means of electron microscope in liver cells and postulated as identical with microsomes separated from other 
constituents of the cell in high speed centrifuge. These microsomes have then been proved to contain also ribonucleic acid and phospholipids (ClaUde, 1941, 1943, 1944, 1946). Ribonucleic acid in the cytoplasm has been found by him (CLAUDE, 1944) to occur only in association with these microsomes and also with mitochondria and other large granules. On treating with crystalline ribonuclease, DAVIDSON and WAYMOUTH (194344) have presumed that ribonucleic acid in the cytoplasm of liver cells is present in the form of particulate components such as mitochondria, microsomes, and secretory granules. Also OPIE $(1946,1947 \mathrm{~b})$ states the relation of ribonucleic acid to mitochondria and cytochondria.

These implications would not be in contradiction with the following interpretation as to the localization of cytoplasmic ribonucleic acid of the liver cell. Cytochondria contain ribonucleic acid. It is more concentrated in the surface layers than in their internal space. Condensed masses of ribonucleic acid localized in the interspace between the cytochondria consist of the submicroscopic microsomes also containing ribonucleic acid. These microsomes are presumably able to enter into the surface layers of the cytochondria and to mingle or to exchange their constituents with those of the cytochondria. The localization of mitochondria may be presumed in the interspace of the cytochondria overlapping spatially with the condensed masses of ribonucleic acid. Indeed, the microsome-like component has been separated by CLAUDE $(1944,1946)$ from mitochondria of leukemic cells or large granules of liver cells. The latter largely consist, without doubt, of the cytochondria. The ribonucleic acid is present in these formed bodies forming various complexes with lipids and proteins, and is coagulated by the usual fixatives. By formalin fixation, however, its localization would not be altered so vigorously, as is maintained by RIEs (1935) or LORETI e PERRONCITo (1938) on the filamentous ergastoplasm of pancreas or parotids, because very fine and delicate basophile structures are demonstrated in the hepatic cytoplasm appropriately fixed and stained according to the physiological and pathological conditions.

Recently, it has become more and more convincing that the metabolic consumption of body proteins may be promoted considerably by infections and other injuries (CANNON, 1944, 1945a, b, ; WILENSKY, 1945; SPRINZ, 1946; HImsworth, 1946; and STARE, 1947). The type II described previously represents presumably the state of the liver reacting to the factors promoting such consumption of proteins. In this state the ribonucleic acid spread over the whole cytoplasm, occupying all the surface of the cytochondria. Thus the reaction surface of the ribonucleic acid is extended to the maximum, what suggests urged decomposition and probably resynthesis of ribonucleic acid and proteins.

The enlargement of cytochondria by mutual fusion as observed in 
type III introduces the diminution of their surface. Moreover, there is a remarkable decrease of the concentration of ribonucleic acid in this state. Consequently, the resistance of animals must fall in these circumstances so considerably that the last "catastrophe" will take place shortly.

As to the mechanism of the enlargement of the cytochondria, OPIE $(1947 \mathrm{~b})$ seems to have related their pathological enlargement with their hydropic swelling produced by immersion of small pieces of tissues in distilled water or hypotonic solutions. But the pathological enlargement of the cytochondria should not be considered in such a mechanical manner, because the living protoplasm may be expected to regulate the osmotic permeability under consumption of energy. Indeed, the rim of the cytochondria is "living" or in an active state performing respiration and metabolism. Moreover, OPIE's interpretation of his experiments with hypotonic solutions seems not to be without liability to criticism, because the supravital immersion of small pieces of tissues in hypotonic solutions involves inevitably the extraction of water-soluble ribonucleoproteins from the cytoplasm and the postmortal autolysis which must be accelerated by the injurious action of the hypotonic solutions. The eniargement of the cytochondria may be more appropriately considered in relation with the mutual fusion caused by changes of their surface properties.

Real hydropic swelling seems to occur rather in the recovering state represented by the type IV. Its large vacuoles have no definable rim, thus possessing no animate boundaries of their own composed of "living" protoplasm, which would be able to regulate permeability of various substances by virtue of their active energy metabolism.

It is somewhat doubtful whether actual increase and decrease of the number of the cytochondria are involved throughout the changes described as types I-IV, because also contraction or enlargement of cell bodies takes place during these changes. The relative changes of the quantity of the cytochondria to the volume of the cell bodies must be distinguished from the real changes of their number, although decrease of the cytochondrial number may be presumed to occur by the mutual fusion of them in type III.

\section{Summary}

1. The difference of the staining behavior of nucleoproteins contained in chromatin and ergastoplasm or nucleoli against several basic dyes (pyronine-methyl green, thionine, etc.), which has recently been discussed by the author $(1948 \mathrm{a}, \mathrm{b}, \mathrm{c})$, may be distinguished terminologically as follows: chromatin is eubasophile while ergastoplasm and nucleoli are heterobasophile.

2. The morphological changes of heterobasophile ergastoplasm (ribo- 
nucieic acid) and cytochondria of liver cells under normal and pathological conditions have been classified into four main types and described in detail. The important characteristics of these types consist in appearance, disappearance, and distribution of the ribonucleic acid and relative quantity and dimension of the cytochondria. The four types may, for convenience sake, be called 1 . normal type, 2. reacting type, 3 . mortal type or "catastrophe,", and 4. recovering type.

3. The nucleotide and protein natures of ergastoplasm and their implications in cell metabolism, the localization of ribonucleic acids in the cytoplasm, the relation of the morphological changes of ergastoplasm and of cytochondria to pathological consumption of body proteins, and the mechanisms of pathological enlargement of cytochondria have been discussed.

Lastly, it is my pleasant duty to express my hearty thanks to Dr. O. Minouchi who led me into this field of cytology always helping me with very instructive and valuabe advice throughout the course of this study. I am also indebted to the members of Medico-Biological Institute of Minophagen Pharmaceutical Co., and especially to Messrs. I. Sato, Zoölogical Institute of Kyoto University, and T. HAMA, Zoölogical Institute of Tokyo University, for their kind assistance and criticism.

\section{Medico-Biological Institute of Minophagen Pharmaceutical Co.}

\section{Bibliography}

Baba, T., Inaba, T., and Kumamura, M., 1933. Trans. Soc. Pathol. Japon. 23 ; 350.

Barnes, F. W., Jr., and Schoenheimer, R., 1943. J. biol. Chem. 151: 123.

Berg, W., 1912. Anat. Anz. 42: 251.

- 1920. Arch. f. mikrosk. Anat. 94: 518.

- 1922. Pflüg. Arch. 195: 543.

- 1928. Zeit. mikrosk.-anat. Forsch. $12: 1$.

Brunes, M., Tracy, M. M., and Cohn, W. E., 1944. J. biol. Chem. 155 : 619.

Cannon, P. R., 1944. J. Mich. State Med. Soc. $43: 323$.

- 1945 a. J. Am. Med. Assoc. 128: 360.

- 1945 b. J. Allergy $16: 78$.

- 1945 c. Advances in protein chemistry 2: 135.

Caspersson, T., 1941. Naturwissenschaften $29: 33$.

Clara, M., 1934. Zeit. f. Zellforsch. u. mikrosk. Anat. 21 : 119.

Claude, A., 1941. Cold Spring Harbor Symposia on quant. Biol. 9 : 263.

- 1943. Frontiers in cytochemistry, Biol. Symposia 10: 111.

- 1944. J. exptl. Med. 80: 19.

- 1946. J. exptl. Med. 84: 51, 61.

Claude, A., and Fullam, E. F., 1946. J. exptl. Med. 83 : 499.

Davidson, J. N., and Waymouth, C., 1943-44. Proc. Roy. Soc. Edinburgh 62 (1) : 96.

Garnier, Ch., 1899. Contribution á l'étude de la structure et du fonctionnement des cellules glandulaires séreuses. Du rôle de l'ergastoplasme dans la sécrétion. Thése de doctorat en médicine, Nancy.

Himsworth, H. P., 1946. Proc. Roy. Soc. Med. 40: 27. 
Loreti, F., e Perroncito, G., 1938. Zeit. f. Zellforsch. u. mikrosk. Anat. 28 : 12.

Metcoff, J., and Stare, F. J., 1947. New Engl. J. Med. 236: 26, 68.

Moribe, R., 1933. Trans. Soc. Pathol. Japon. $23: 412$.

Opie, E. L., 1946. J. exptl. Med. 84: 91.

- 1947 a. J. exptl. Med. 85: 339.

- 1947 b. J. exptl. Med. 86, 45.

Opie, E. L., and Lavin, G. I., 1946. J. exptl. Med. 84: 107.

Ries, E., 1935. Zeit. f. Zellforsch. u. mikrosk. Anat. 22: 523.

- 1938. Grundriß der Histophysiologie. Leipzig.

Schoenheimer, R., 1942. The dynamic state of body constituents. Harvard Univ. Monogr. in Med. and Publ. Health. 3.

Schoenheimer, R., and Rittenberg, D., 1936. J. biol. Chem. 114: 381.

Sibatani, A., 1947. Rironseibutugaku (Theoretical Biology.), 2. ed. Kyoto.

- 1948 a. Igaku to Seibutugaku (Tokyo) in press.

- 1948 b. Zool. Mag. (Tokyo) in press.

- 1948 c. Ibid. in press.

Solger, B., 1896. Festschrift f. Carl Gegenbauer 2: 181.

Sprinz, H., 1946. Med. Clin. North Am. 30: 363.

Wilensky, A. O., 1945. Intern. Abstr. Surg., suppl. Surg. Gyn. Obstr. 80 : 323.

Worley, L. G., 1946. Ann. New York Acad. Sci. $47: 1$. 